\title{
Daily Math : From Concepts to Habits
}

\author{
Wanda Nugroho Yanuarto \\ Universitas Muhammadiyah Purwokerto \\ Email : wandanugroho86@gmail.com
}

\begin{abstract}
Math expresses itself everywhere, in almost every face of life, in nature all around, and in the technologies in hands. Mathematics is the language for the universe. The purpose of this study are introducing math in concept and deliver it into application life for students. The situational problem as the starting point helps students to relate what they learn to problems in daily life, and construct that are related to real situations. It is take place in math education subject in Teacher Training and Education Faculty at The University of Muhammadiyah Purwokerto, Indonesia. Authors start with projects that have applications of math and continue with the closely related topic of concept math. Then go on to the timely topic of concepts of math (exponents, multiplying \& dividing integers, multiplying decimals, and percent), the application of which are immediately felt when the students face in cooking by numbers, home decorating, populating growth, saving \& credit, and playing to win. It presents four projects in home, restaurant, school or college, and bank. In the section on society it touch upon topics like cooking recipe, decorating a house, populating, account saving, and probability issues.
\end{abstract}

Keyword: Math, concepts of math, habits of math

\section{INTRODUCTION}

Mathematics is in principle inexpensive. As the old joke says, a mathematician needs only paper, a pencil, an easy chair and a waste basket. Also, the criterion for success in mathematics is by and large universally accepted. This makes mathematics an attractive 'investment' (Hoffman, 1997; Brookhart, 1998; Gullberg, 1997). Moreover, a mathematical result is valid forever. It may fall out of fashion, or fall outside the current area of application, but even the oldest known mathematical formulae - such as that for solving quadratic equations, known 2400 years ago by Babylonians, Chinese and later the Greeks before being crystallized into its present form in $1100 \mathrm{AD}$ by a Hindu mathematician called Baskhara - are the bread and butter of present-day elementary mathematics. Mathematics can be compared to a pyramid. On the top of the pyramid are applications of mathematics to health, weather, movies and mobile phones. However the top of this pyramid would not be so high if its base were not so wide. Only by extending the width of the base can we eventually build the top higher (Devlin, 1998; Guedj, 1998; Dehaene, 1997). This special feature of mathematics derives from its internal structure. A good modern application of mathematics can typically draw from differential equations, numerical analysis and linear algebra. These may very well draw from graph theory, group theory and complex analysis. These in turn rest on the firm basis of number theory, topology and geometry. Going deeper and deeper into the roots of the mathematics, one ends up with such cornerstones of logic as model theory and set theory. 
It is clear that mathematics is heavily used in large industrial projects and in the ever-growing electronic infrastructure that surrounds us. However, mathematics is also increasingly infiltrating smaller scale circles, such as doctors' reception rooms, sailboat design and of course all kinds of portable devices. There has also been a change in the way mathematics penetrates our society. The oldest applications of mathematics were probably in various aspects of measurement, such as measuring area, price, length or time. This has led to tremendously successful mathematical theories of equations, dynamical systems and so on. In today's world, we already know pretty accurately for example the make-up of the human genome, yet we are just taking the first steps in understanding the mathematics behind this incredibly complex structure of three billion DNA base pairs (Conway, 1997; Singh, 1998). Our understanding of the mathematics of the whole universe of heavenly bodies, even going back in time to the first second of its existence, is better than our understanding of the mathematics of our own genes and bodies. What is the difference between the hereditary information encoded in DNA and the information we have about the movements of the heavenly bodies? Is it that we have been able to encapsulate the latter into simple equations, but not the former? Or is it perhaps that the latter has a completely different nature than the former, one that makes it susceptible to study in terms of equations, while the former comes from a world governed by chance, and algorithms, a world of digital data, where the methods of the continuous world do not apply?

Another well-known instance of mathematics in society is cryptography in its various guises. There exist numerous situations in which data must be encrypted such that it can be publicly transmitted without revealing the content. On the other hand, sometimes a party may find it vitally important to break a code that another party has devised for its protection. Some companies want to examine the data of our credit card purchases in order to have access to our shopping patterns (Guillen, 1996; Dunham, 1991). Some governments want to do the same with regard to what they deem less innocuous patterns of behavior. Cryptography is a typical example of the mathematics of the digital world. Digital data has become important in almost all fields of learning, a natural consequence of advances in computer technology. This has undoubtedly influenced the way students look at fields of mathematics such as number theory, that were previously thought to be very pure and virtually devoid of applications, good or bad. Now suddenly everybody in the possession of big primes has someone looking over their shoulder.

This infiltration is quite remarkable and elevates mathematics to a different position from that which it previously occupied. Mathematics is no longer a strange otherworldly subject, practiced by a few curious geniuses but for most students best left alone. The spread of microprocessors into every conceivable aspect of our everyday life has brought heavy-duty computing into our homes, into our classrooms and into scientific laboratories of all kinds. Naturally it is unnecessary for everyone to understand all this computing, which can take place in microseconds without our noticing (Stewart, 1998; Dunham, 1997). But it means that anyone who refuses to acknowledge the role of mathematics will see the changing technosphere as something strange and in the worst case as something irrational or even frightening. A very good way to understand and come to terms with an important aspect of modern 
life our ever-growing dependence on interpreting digital data is to have a basic knowledge of mathematics.

Basic knowledge: what does this mean and how is it attained? Clearly, this takes us into the realm of mathematics education. Strictly speaking, education is not an application of mathematics, but it is nevertheless of increasing importance to the mathematical world (Paulos, 1996). Without attempting to answer this difficult question, one must admit that it is important and that math education will face huge challenges in the future, not least because of the infiltration of mathematics into all levels of society. This infiltration clearly has much to do with the revolution triggered by the development of computers over the last fifty years. Has this revolution arrived in schools, and in math education? Most students now own a computer with an Internet connection. This is used for games, chatting, text processing and surfing, but do they use the computer for mathematics? Are mathematical modeling (ambitious problem solving) or algorithmic thinking (expressing mathematics in such a way that the computer can handle it) taught at school? There is much that can be done here, in curricula, in textbooks and in everyday life at school.

Even those suffering from math-related anxieties or phobias cannot escape its everyday presence in their lives. From home to school to work and places inbetween, math is everywhere. Whether using measurements in a recipe, or deciding if half a tank of gas will make the destination, we all use math. It is a good idea, therefore, for teachers and parents of reluctant math learners to use real world examples to ignite a spark of practical interest, such as:1) At Home, some students aren't even out of bed before encountering math. Setting an alarm and hitting snooze, they may quickly need to calculate the new time they will arise. Or they might step on a bathroom scale and decide that they'll skip those extra calories at lunch. Students on medication need to understand different dosages, whether in grams or milliliters. Recipes call for ounces and cups and teaspoons --all measurements, all math. And decorators need to know that the dimensions of their furnishings and rugs will match the area of their rooms; 2) In Travel, travelers often consider their miles-per-gallon when fueling up for daily trips, but they might need to calculate anew when faced with obstructionist detours and consider the cost in miles, time and money. Air travelers need to know departure times and arrival schedules. They also need to know the weight of their luggage unless they want to risk some hefty baggage surcharges. Once on board, they might enjoy some common aviation-related math such as speed, altitude and flying time; 3) At School and Work, students can't avoid math -- most take it every day. However, even in history and English classes they may need to know a little math. Whether looking at time expanses of decades, centuries or eras or calculating how they'll bring that B in English to an A, they'll need some basic math skills (Wells, 1997; Bantam, 1998).

Jobs in business and finance may require sophisticated knowledge of how to read profit and earning statements or how to decipher graph analyses. However, even hourly earners will need to know if their working hours times their rate of pay accurately reflects their paychecks; 4) At the Store, whether buying coffee or a car, basic principles of math are in play. Purchasing decisions require some understanding of budgets and the cost and affordability of items from groceries to houses. Short-term decisions may mean 
only needing to know cash-at-hand, but bigger purchases may require knowledge of interest rates and amortization charts. Finding a mortgage may be much different than choosing a place to have lunch, but they both cost money and require math; 5) Pastimes, even off-time can be math time. Baseball fans know a lot about statistics, whether they're considering basic win-loss ratios, batting averages or pitchers' earnedrun-averages. Football fans know about yardage gains and passing stats. And individual athletes, whether runners, bikers, sailors or hikers, often have their own ways of charting their progress, from time to mileage to elevation (Blatner, 1997; Brookhart, 1998).

\section{METHODS}

In this special issue on Mathematics for Everyday Life, it presents a selection of mathematical projects that are in some way relevant, directly or indirectly, to everyday lives. It is take place in math education subject in Teacher Training and Education Faculty at The University of Muhammadiyah Purwokerto, Indonesia. Authors start with projects that have applications of math and continue with the closely related topic of concept math. Then go on to the timely topic of concepts of math (exponents, multiplying \& dividing integers, multiplying decimals, and percent), the application of which are immediately felt when the students face in cooking by numbers, home decorating, populating growth, saving \& credit, and playing to win. It presents four projects in home, restaurant, school or college, and bank. In the section on society it touchs upon topics like cooking recipe, decorating a house, populating, account saving, and probability issues.

\section{RESULT AND DISCUSSION}

\section{A. RESULT}

How can math be so universal? First, human beings didn't invent math concepts; we discovered them. Also, the language of math is numbers, not English or German or Russian. If math well versed in this language of numbers, it can help to make important decisions and perform everyday tasks. Math can help to shop wisely, buy the right insurance, remodel a home within a budget, understand population growth, or even bet on the horse with the best chance of winning the race. In developing an awareness of mathematical concepts to habits, students must engage their concept skills first. Some concepts lend themselves to 'visualization', creating a mental image to represent a mathematical relationship. The concept of proportion is a good example. A student may have a difficult time interpreting proportion through words and verbal explanation, but being able to visualize the relationship (e.g., the number of boys to girls in the class, the ratio of eaten slices in a pizza) may greatly enhance his/her understanding of proportion as a concept. Here are some concepts to help students develop and strengthen they use for daily activities in life: Exponents, exponents are a shorthand way to show how many times a number, called the base, is multiplied times itself. A number with an exponent is said to be "raised to the power" of that exponent. An exponent tells students how many times the base number is used as a factor. A base of five raise to the second power is called "five squared" and means "five times five." Five raised to the third power is called "five cubed" and means "five times five times five." The base can be any sort of number--a whole number, a decimal number, or a fraction can all be raised to a power. These are mistakes that students often make when dealing with exponents : a) Do not multiply the base and the exponent. 26 is not equal to 12 , it's $64 ; b$ ) 
The multiplication rule only applies to expressions with the same base. Four squared times two cubed is not the same as 8 raised to the power two plus three.

$$
\begin{aligned}
4^{2} \times 2^{3} & \neq 8^{2+3} \\
(4)(4) \times(2)(2)(2) & \neq 8^{5} \\
128 & \neq 32,768
\end{aligned}
$$

Figure 1. Multiplication mistake in exponents c) The multiplication rule applies just to the product, not to the sum of two numbers

$$
\begin{gathered}
2^{2}+2^{3} \neq 2^{1+3} \\
(2)(2)+(2)(2)(2) \neq 2^{5} \\
4+8 \neq(2)(2)(2)(2)(2 \\
12 \neq 32
\end{gathered}
$$

Figure 2. Multiplication for sum of two numbers

Multiplying and dividing integers, to multiply or divide signed integers, always multiply or divide the absolute values and use these rules to determine the sign of the answer. When students multiply two integers with the same signs, the result is always positive. Just multiply the absolute values and make the answer positive.

\section{Positive $x$ positive $=$ positive \\ Negative $x$ negative $=$ positive}

When students multiply two integers with different signs, the result is always negative. Just multiply the absolute values and make the answer negative.

Positive $x$ negative $=$ negative

Negative $x$ positive $=$ negative
When students divide two integers with the same sign, the result is always positive. Just divide the absolute values and make the answer positive.

$$
\begin{gathered}
\text { Positive } \div \text { positive }=\text { positive } \\
\text { Negative } \div \text { negative }=\text { positive }
\end{gathered}
$$

When students divide two integers with different signs, the result is always negative. Just divide the absolute values and make the answer negative.

$$
\begin{aligned}
& \text { Positive } \div \text { negative }=\text { negative } \\
& \text { Negative } \div \text { positive }=\text { negative }
\end{aligned}
$$

Multiplying decimals, to multiply decimal numbers are: 1) multiply the numbers just as if they were whole numbers: (a) line the numbers on the right (do not align the decimal points); (b) starting on the right, multiply each digit in the top number by each digit in the bottom number, just as with whole numbers; (c) add the products; 2)place the decimal point in the answer by starting at the right and moving a number of places equal to the sum of the decimal places in both numbers multiplied. For example is:

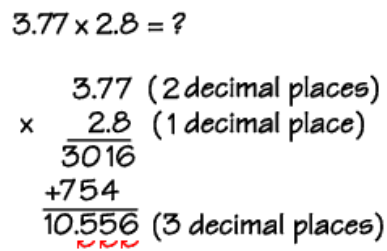

Figure 3. Multiplying decimals' example In this problem, students must use their estimating skills as well as their multiplying skills. 


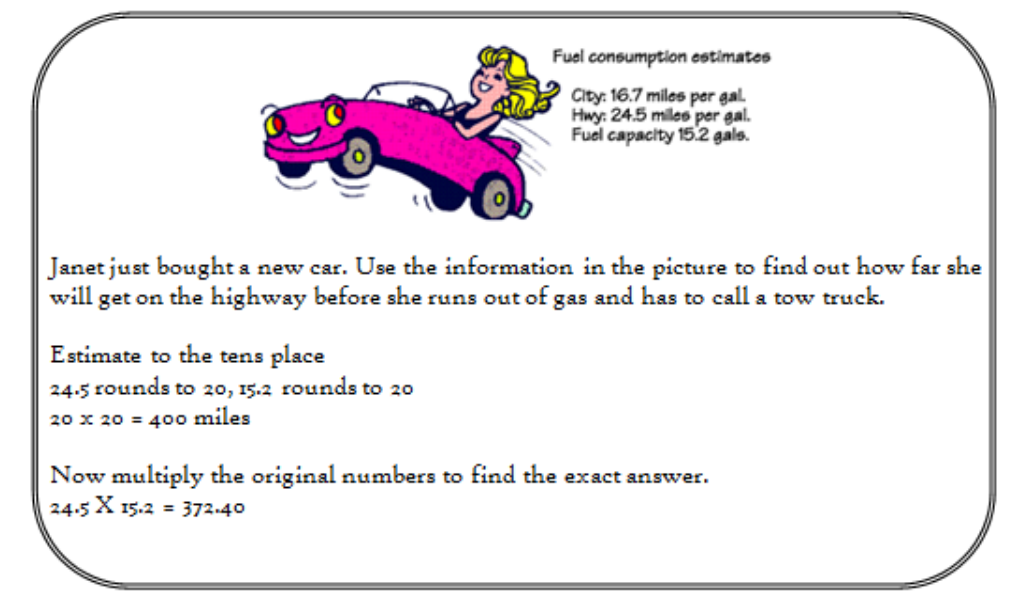

Figure 4. One multiplying decimals' problem

Percent, means "out of 100." Students can use the percent symbol (\%) as a handy way to write a fraction with a common denominator of 100. For example, instead of saying "8 out of every 100 professional basketball players are female," students can say " $8 \%$ of professional basketball players are female." A percent can always be written as a decimal, and a decimal can be written as a percent, by moving the decimal point two places to the right like this:

$$
0.85=0.85=85 \%
$$

Figure 5. Example for decimal moving to percent

Students use the percent symbol (\%) to express percent. Percents are used everywhere in real life, so students will need to understand them well. Here are three ways to write the same thing:

$$
15 \%=15 / 100=0.15
$$

Fifteen percent is the same as the fraction 15/100 and the decimal 0.15. They all simply mean "fifteen out of a hundred." A percent can always be written as a decimal, and a decimal can be written as a percent, like this:

$$
0.85=85 \%
$$

We can find any percent of a given number by changing the percent to a decimal and multiplying. One hundred percent of a number is just the number itself. Two hundred percent of a number is twice that number.

$$
\begin{aligned}
& 100 \% \text { of } 50=50 \\
& 200 \% \text { of } 50=2 \times 50=100
\end{aligned}
$$

After students have learned about math concept (exponents, multiplying and dividing integers, multiplying decimals, and percent) that use for their daily activity in life. The project explores how math can help students in their daily lives. In this section, math can be a language of numbers through common situations, such as playing games or cooking. Put decisionmaking skills to the test by deciding whether buying or leasing a new car, and predict how much money they can save for retirement.

\section{Cooking by numbers}

Not all students are chefs, but all students are all eaters. Most of them need to learn how to follow a recipe at some point. To create dishes with good flavor, consistency, and texture, the various ingredients must have a kind of relationship to one another. For instance, to make cookies that both look and taste like cookies, they need to make sure use the right amount of each ingredient. Add too much flour and their cookies will be solid as rocks. Add too much salt and they'll taste terrible.

Ratios: Relationships between quantities 
That ingredients have relationships to each other in a recipe is an important concept in cooking. It's also an important math concept. In math, this relationship between 2 quantities is called a ratio. If a recipe calls for 1 egg and 2 cups of flour, the relationship of eggs to cups of flour is 1 to 2. In mathematical language, that relationship can be written in two ways: $1 / 2$ or $1: 2$. Both of these express the ratio of eggs to cups of flour: 1 to 2 . If the chefs mistakenly alter that ratio, the results may not be edible.

\section{Working with proportion}

All recipes are written to serve a certain number of students or yield a certain amount of food. It might come across a cookie recipe that makes 2 dozen cookies, for example. What if students only want 1 dozen cookies? What if students want 4 dozen cookies? Understanding how to increase or decrease the yield without spoiling the ratio of ingredients is a valuable skill for any cook. Let's say students have a mouth-watering cookie recipe as the image below:

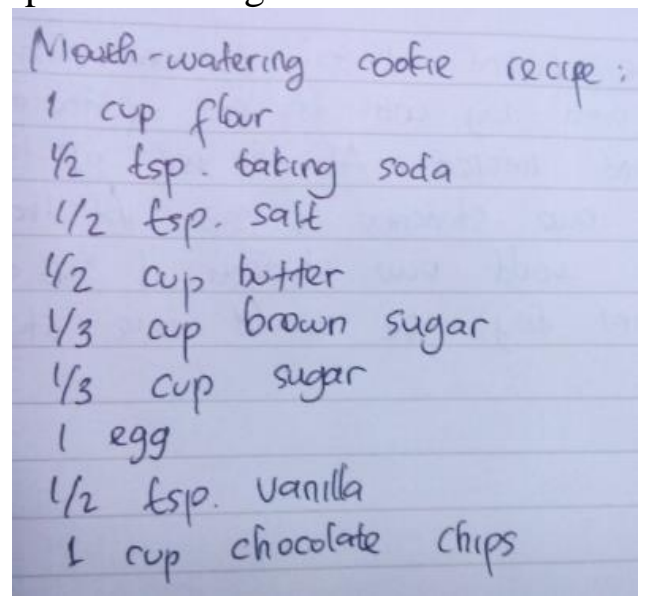

Figure 6. Students' experiment for making cookie

This recipe will yield 3 dozen cookies. If students want to make 9 dozen cookies, they will have to increase the amount of each ingredient listed in the recipe. They will also need to make sure that the relationship between the ingredients stays the same. To do this, they will need to understand proportion. A proportion exists when students have 2 equal ratios, such as 2:4 and 4:8. Two unequal ratios, such as 3:16 and 1:3, don't result in a proportion. The ratios must be equal. Going back to the cookie recipe, how will students calculate how much more of each ingredient they'll need if students want to make 9 dozen cookies instead of 3 dozen? How many cups of flour will need? How many eggs? they'll need to set up a proportion to make sure the ratios right.

$$
\frac{1 \text { cup flour }}{x \text { cups flour }} \times \frac{3 \text { dozen }}{9 \text { dozen }}
$$

It can be read this proportion as " 1 cup of flour is to 3 dozen as $x$ cups of flour is to 9 dozen." To figure out what $x$ is (or how many cups of flour the chef will need in the new recipe), they'll multiply the numbers like this:

$$
\begin{aligned}
x \text { times } 3 & =1 \text { times } 9 \\
3 x & =9
\end{aligned}
$$

Now all chef have to do is find out the value of $x$. to do that, divide both sides of the equation by 3 . The result is $x=3$. To extend the recipe to make 9 dozen cookies, they will need 3 cups of flour. What if make 12 dozen cookies? Four dozen? Seven-and-a-half dozen? Set up the proportion above, regardless of how much they wanted to increase the recipe.

\section{Home decorating}

What does math have to do with home decorating? Most home decorators need to work within a budget. But in order to figure out what students will spend, they first have to know what they need. How will they know how many rolls of wallpaper to buy if they don't calculate how much wall space they have to cover? Understanding some basic geometry can help they stick to their budget. 
Figuring area: Squares and rectangles

Imagine students are planning to buy new carpeting for home. They are going to put down carpeting in the living room, bedroom, and hallway, but not in the bathroom. They could try to guess at how much carpet they might need to cover these rooms, but better off figuring out exactly what it need. To determine how much carpet will need, use this simple formula:

$$
A=L \times W
$$

Or in other words, "area equals length times width." This formula is used to determine the area of a rectangle or square. In the floor plan below, all of the floor space (as well as the walls and ceilings) is made up of squares or rectangles, so this formula will work for figuring the area students need to carpet.

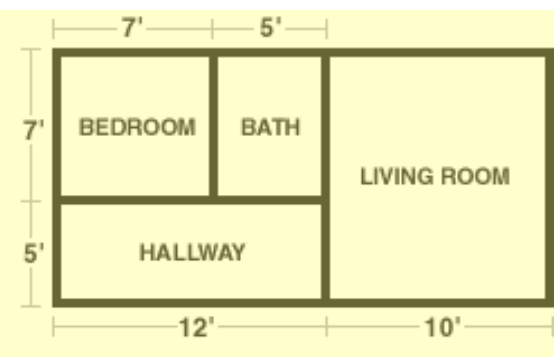

Figure 7. Home's decorating

Start by figuring the total area of the floor plan. When it done, deduct the area of the bathroom, since it is not want to carpet that room. To figure out the total area of the floor plan, need to know the total length and width. The total length of the floor plan shown above is 12 feet plus 10 feet, or 22 feet. The total width is 7 feet plus 5 feet, or 12 feet. Plug these numbers into equation to get the total area of the floor plan.

$$
\begin{gathered}
A=22 \text { feet } \times 12 \text { feet } \\
A=264 \text { square feet }
\end{gathered}
$$

The total area of floor plan is 264 square feet. Now need to figure out the area of the bathroom so deduct it from the total area. The bathroom is 7 feet long and
5 feet wide, so it has an area of 35 square feet. Deducting the area of the bathroom from the total area (264 minus 35) leaves students with 229 square feet to carpet.

\section{Figuring area: Circles}

Calculating how much carpet will need is a fairly simple task if home has only square or rectangular rooms. But what if have a circular alcove at the end of one room? Geometry comes to the rescue again with a handy formula:

$$
A=\pi r^{2}
$$

In English, this formula means "area equals pi times the radius squared." A circle's radius is one half of its diameter or one half of what get if measure all the way across its widest part. "Squaring" something means multiply it by itself. $\mathrm{Pi}$ is a number that roughly equals 3.14159.

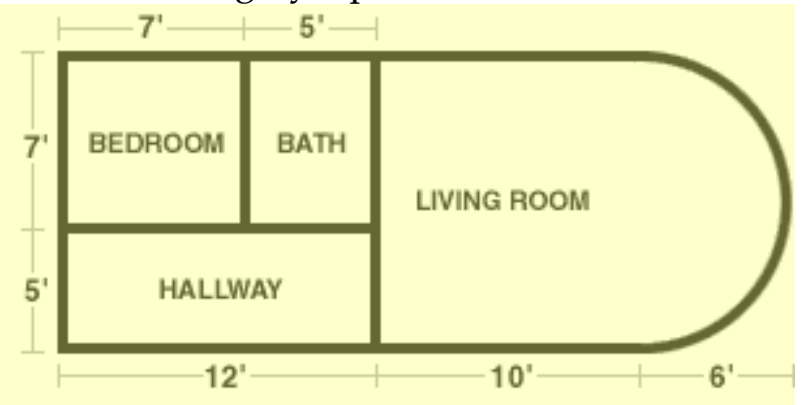

Figure 8. Home's decorating

If living room has a semi-circular alcove as shown in the floor plan above, it need to use this additional equation to figure out its area. To figure the radius of alcove, the number it need to plug into the equation, divide its diameter in half. Its diameter is the same as the width of the living room: 12 feet. Half of that is its radius: 6 feet. Let's plug in the numbers:

$$
\begin{gathered}
\quad A=3.14159 \times(6 \text { feet } \times 6 \text { feet }) \\
A=113 \text { square feet } \\
\text { (rounded to the closest square foot })
\end{gathered}
$$

If the alcove were a complete circle, it would have an area of 113 square feet. Because it's a half circle, its area is half of that, or 56.5 square feet. Adding 56.5 square feet to the rest of the floor plan's 
area of 229 square feet gives total area to carpet: 285.5 square feet. Using geometry,

\begin{tabular}{|c|c|}
\hline Year & Population \\
\hline 1700 & 600.000 .000 \\
\hline 1800 & 900.000 .000 \\
\hline 1900 & 1.500 .000 .000 \\
\hline 2000 & 6.000 .000 .000 \\
\hline
\end{tabular}

it can buy exactly the amount of carpet's need.

\section{Populating growth}

In the last few centuries, the number of students living on Earth has increased many times over. By the year 2000, there will be 10 times more students on Earth than there were 300 years ago. How can population grow so fast? Think of a family tree. At the top are 2 parents, and beneath them the children they had. Listed beneath those children are the children they had, and so on and so on, down through each generation. As long as the family members continue to reproduce, the family tree continues to increase in size, getting larger with each passing generation. This same basic idea applies to the world's population.

\section{Exponential growth: How fast will it grow?}

Population grows in the same way that money grows when it's left to compound interest in a bank. With money, growth comes through accumulating interest upon interest. The interest payments accumulate eventually earn interest, increasing money. With population growth, new members of the population eventually produce other new members of the population. The population increases exponentially as time passes. A crucial difference between money and population is that money can increase without limits while population can't. Any population of living creatures is constrained by the availability of food, water, land, or other important resources. Once those resources are depleted, a population won't continue to grow exponentially. It will plateau, or even decline, as a result of disease or malnutrition. Unlike calculating interest, calculating population growth is an imprecise business.

Table 1. World Population

To arrive at a reasonable estimate of how the world's population will grow in the next 50 years, look at birth and death rates (the rates at which students are being born and dying in any given period). If birth and death rates stayed the same across the years in all parts of the world, population growth could be figured with a fairly simple formula much like the one used to figure compound interest. Birth and death rates aren't constant across countries and through time, however. Disease or disaster can cause death rates to increase for a certain period. A booming economy might mean higher birth rates for a given year.

The rate of Earth's population growth is slowing down. Throughout the 1960s, the world's population was growing at a rate of about $2 \%$ per year. By 1990, that rate was down to $1.5 \%$, and by the year 2015 , it's expected to drop to $1 \%$. Family planning initiatives, an aging population, and the effects of diseases such as AIDS are some of the factors behind this rate decrease. Even at these very low rates of population growth, the numbers are staggering. By 2015, despite a low expected $1 \%$ growth rate, experts estimate there will be 7 billion students on the planet. By 2050, there may be as many as 10 billion students living on Earth. Can the planet support this population? 
Saving and credit: Understanding the basics

Many students collect only 1 to $3 \%$ interest on money in a savings account while simultaneously paying rates as high as 18 to $20 \%$ on credit card balances. Over time, this can mean some pretty heavy losses. With some math smarts and an understanding of simple and compound interest, manage the way their money grows (and ideally keep it from shrinking). The principles of simple and compound interest are the same whether calculating the earnings from a savings account or the fees being accumulated on a credit card. Paying a little attention to these principles could mean big payoffs over time.

When students put money in a savings account, the bank pays according to what they deposit. In effect, the bank is paying students for the privilege of "borrowing" their money. The same is true for the interest they pay on a loan from the bank or the money they "borrow" from a credit card. Interest is expressed as a rate, such as $3 \%$ or $18 \%$. The dollar amount of the interest they earn on a savings account is figured by multiplying the money they deposit (called the principal) by the rate of interest. If students have $\$ 100$ in an account that pays only $1 \%$ interest, only earn $\$ 1$ in interest. If students shop around for an account that pays 5\% interest, they will earn five times that amount. In banking, interest is calculated and added at the end of a certain time period. Savings account that offers a $3 \%$ interest rate annually. At the end of each year, the bank multiplies the principal (the amount in the account) by the interest rate of $3 \%$ to compute what have earned in interest.

\section{Interest on interest: Compounding}

There are two basic kinds of interest: simple and compound. Simple interest is figured once. If students loaned $\$ 300$ to a friend for one month and charged her 1\% interest (\$3) at the end of the month, students'd be dealing with simple interest. Compound interest is a little different. With compound interest, the money students earn in interest becomes part of the principal, and also starts to earn interest. For example we can see as the figure below:

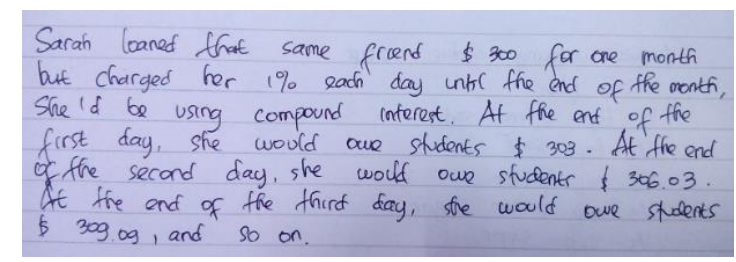

Figure 9. One example from students for compound interest

Compound interest is what makes credit cards and loans so difficult to pay off. The rules of interest are the same ones that increase studentsr savings over time, only with credit and debit, they're in the bank's favor. With some rates as high as $21 \%$, collecting interest on credit card loans can be a lucrative business.

\section{Playing to win}

Each year, millions of students travel to casinos hoping they will come away richer. Many more students visit their local supermarket each day to bet with lottery cards. Students play the stock market, join in the office football pool, and meet with friends on the weekend for a game of poker. Why do students invest this money on chance? because students believe they can beat the odds. Mathematical principles can tell more than whether it is possible to win. They can tell how often likely to win. The mathematical concept that deals with the chances of winning a lottery drawing or a poker game is probability. Determine the probability that a certain event (such as winning the lottery) will occur, make a better choice about whether to risk the odds. 
Determining probability

How do students determine probability? Let's say there are 12 socks in their dresser drawer. Five are red and 7 are blue. If they were to close their eyes, reach into the drawer, and draw out 1 sock, what is the probability that it would be a red sock? Five of the 12 socks are red, so their chances of picking a red sock are 5 out of 12. They can set this up as a fraction or a percentage that expresses the probability of picking a red sock: $5 / 12$ their chances of picking a red sock are 5 out of 12 , or 5 divided by 12 , which is about $42 \%$. Not bad, as odds go.

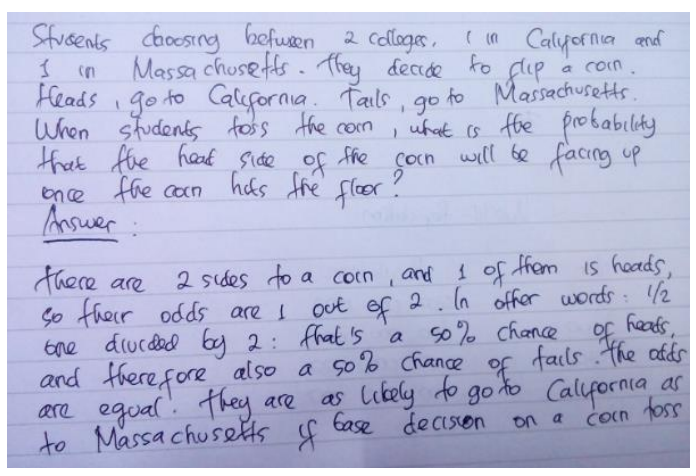

Figure 10. Students example for probability

Even if students don't frequent casinos, they probably play the odds all the time. Students might invest in the stock market. They might buy auto, health, and life insurance as a hedge against the costs of damage or injury. In many cases in which they are trying to predict the future, they are using the mathematics of probability.

\section{B. DISCUSSION}

Math is a part of students' lives, whether clean the house, make supper or mow the lawn. Wherever students go, whatever they do, they are using math daily without even realizing it. It just comes naturally. In the kitchen, baking and cooking requires some mathematical skill as well. Every ingredient has to be measured and sometimes students need to multiply or divide to get the exact amount they need. Whatever they do in the kitchen requires math. Even just using the stove is basic math skills in action. Banking, can students imagine going to the bank and not having any idea what they need to do or how to manage their finances. This will cause a huge disaster in their life, and they will be bankrupt within hours. Decorating home, whether students are painting, doing the flooring or just acquiring new furniture, they need math to make their sums add up. Everything they do inside or outside of their home needs math skills. From accessories to a new swimming pool and putting in new lighting. Statistics, every basic thing students use in life consist of history. That means statistics, taking into account the past and the future, and keeping record of what has been done. Without statistics they won't know what worked and what didn't. it helps students to find balance and structure.

There are so many advantages of math concepts that can students use in their daily activities in life. Many applications that authors shown above are from math concepts. These concept maps are added to as further research in the respective areas are conducted: 1) Probability, is surrounding life. It underpins both statistical investigations and statistical literacy. While the main thrust is on quantitative probability, qualitative probability is also addressed. Key probability ideas and common misconceptions are also covered; 2) Basic facts, this looks at the usual addition, subtraction, multiplication, and division basic facts. It also extends these to larger numbers, and to fractions, decimals and percentages as well. Students who have a good vocabulary of basic facts are able to concentrate on other aspects of mathematical problems; 3) Algebraic 
patterns, the study of patterns is a key part of algebraic thinking. It is important that students are able to recognise and analyse patterns and make generalisations about them. Patterns can be created from shapes, sounds, colours or numbers. They can be visual or spatial, repeating or growing. Students can continue a given pattern, find missing elements, identify general rules, or make up their own pattern; 4) Fractional thinking, this provides a concept map of teaching and learning issues for fractions. It looks at partitioning, part-whole understanding of fractions, equivalence, and fractions as operators. Links to relevant $A R B$ resources are also provided; 5) Algebraic thinking, this concept map highlights key areas of Algebraic thinking that influence students' ability to solve algebraic equations in later years. The concepts covered are equality, additive identity, commutativity, and associativity.

Probability is surrounding life. For example there is a $70 \%$ chance of rain, or that a court case has been decided beyond reasonable doubt (not with certainty you may note). Scientists say that they are $95 \%$ confident that a new medicine is effective, or doctors tell us that there is only a small chance of reacting negatively to a particular drug. It can be debated whether independence, probability, and chance actually exists in the real world. Some students claim that given sufficient information that everything can be exactly predicted or specified. They are called "determinists". Other people claim that the laws of probability do govern at least some physical events. These people follow what is known as "probabilism". Whatever of these two viewpoints is held, probability is a highly effective way of modeling many real life situations.

Probability underpins the other two sub-strands of Statistics in the curriculum. Real-life data is variable, and statistics is the tool to help students cope with this variability. Probability is a way of describing and quantifying how things vary. So probability is not an end in itself, or something that only helps students to gamble, or play games of chance. It is a tool that helps students to investigate the real world we live in, and to respond critically to other students' statistical claims from investigations. Probability investigations also are one way to build up a feel for variability and distribution.

There are two approaches to probability in this situation, such as: 1) The Classical or frequentist approach. These look at probabilities as the relative frequency of the occurrence of events. These are derived either from performing an experiment (where an experimental probability is found) or from enumerating all possible outcomes (where the theoretical probability is derived). Probabilities are usually expressed as fractions or decimal numbers, but also are expressed as percentages. The frequentist model covers discrete events (i.e. those with a set of distinct outcomes, such as the number on a dice) as well to situations where outcomes are measurement (continuous) data such as areas (or angles) on a spinner; 2) The Bayesian approach assigns probabilities to events that are based upon an individuals' degree of belief that something may happen. "The chance of rain today is $70 \% "$ fits into this category. This is not just the weather forecaster's blind faith, but their informed belief, and prior experience. A gambler may think "that horse has a good chance of winning" and go and place a bet on it.

Basic facts, when students think of basic facts, possibly the first thing that springs to mind are our "times tables". But there is far more to them than this. Students should memorize simpler facts, like our addition and subtraction facts. Often these have been ignored. Just maybe $7 \times 8$ may pop into mind just a tad more 
automatically than $7+8$. The main ones encountered are the whole-number basic facts, and in particular addition and multiplication, and their close cousins subtraction and division. Growing number of instantly recognizable or retrievable facts into basic math factual knowledge (basic facts). For example, it is highly useful to instantly equate the fact that $1 / 2$, 0.5, and $50 \%$ are alternative representations of the same amount. Understanding and strategies are the most important aspects for basic facts, but this does not exclude the role of memorization. Each one helps the other. Start with strategies, authors has shown that it is inefficient to try and remember facts which do not have a firm meaning to the student. There is little point trying to get a student to learn their times-tables if they have no understanding of multiplication. Students should also have a strategy, or preferably a range of strategies that they understand and can use to obtain the result that we want them to eventually memorize. Basic facts should not just be rote-learnt in isolation from understanding. There is little point knowing what $6+7$ or $7 \times 8$ is, if the student has no concept of addition or of multiplication. Authors need the joint foci on developing understanding as well as memory.

Plenty of practice, Doing a wide variety of work that aims to build and enhance strategies, helps reinforce procedures, and understanding of mathematics. Practicing strategies also reinforces and continues the process of memorization. Move on to memorize the basic facts, Memorizing means that the student has fast recall without returning to any strategy. This should only come after the students understand the operation, and have some strategies for performing it.

For daily life, students would be quite strenuous without math knowledge. There are many ways in which people use math during the day today living. Below are some ways in which people use math in daily life. To begin with, students need to be able to organize and count their money; as well as subtract, divide and multiply. This is a skill everyone needs to have in order to survive. Every day students visit supermarkets to buy items, without math's knowledge, they would not be able to know if they have been given the right change. Some activities in class require basic math"s knowledge for them to be done effectively. For example, a person needs to work out the amount of materials required in order to decorate a house. One has to be aware of the measurement, space and shape of the area he is working on to ensure that he or she has purchased the required amount of materials. This helps in ensuring that you do not run out of essential materials before the job is finished or do not have too much left over. In the field of architecture or engineering, it is essential to have more advance math's knowledge. Working on geometry and algebra helps in reasoning skills and assist later in life to solve technical problems. Several other jobs also require workers to apply math, such as building and construction, scientist, plumber, electrician, accountant and even rally drivers. Jobs which do not use math every day still require some basic knowledge of mathematics to complete certain tasks. Some students might be against this , but it is advisable for everyone to learn basic mathematic skills. Whether believe or not, sports do rely greatly on math. Managers, players and even supporters ought to have some basic math knowledge. The math's concept can apply when one wants to comment about the game, the player's analysis and much more. Referees and coaches make calls which are based on time, statistics and percentage all the past 
game played and players, their failure and success rates can only be worked out using some aspects of math.

\section{CONCLUSION}

The conclusions of math in daily life are the answers to math problems that all use in the course of our daily lives. For example, figuring out how much a drink and a meal at a restaurant will cost is a conclusion that helps someone to decide whether or not they can afford to order what they want at a dining establishment. Figuring out how much ten per cent off is on a pair of pants is another conclusion that assists a consumer with making a solid decision about plunking down their hard-earned cash and buying the garment. Math conclusions are constant, students use math in all of the time, whether consciously or unconsciously; for example, looking at our watches and calculating when buses or subways will arrive at our destinations, or our bus stops or subways stops, is a form of mental calculation that we do almost every day, sometimes without really consciously thinking about it. Math is vital in industry, in engineering, in retail, and in medicine. Basically, math is crucial in every form of living and every form of job. Learning math, In math, it's really important to be accurate, but some students do struggle with coming up with the correct conclusions to everyday problems. If there is someone who has trouble learning math and needs some help, students may want to consider hiring a tutor, or at least carrying a great handheld calculator along grocery shopping or doing other tasks. Math is one of the building blocks of human knowledge and social progress, without proper calculations and math conclusions, it is not possible to estimate or to budget properly. The best math students and everyday mathematicians practice regularly so that they can master the practical processes of math.

As a researcher, examining these questions has suggested some answer but has raised many more questions. How applicable is the teaching and learning activity based on a math concept to habits. How does the implementation of math concept to habits in Math Education Students in Muhammadiyah University of Purwokerto? Finally, I hope this research will stimulate others to continue the research, verify, modify, or apply it.

\section{REFERENCES}

Hoffman, Paul. (1997). Archimedes' Revenge: The Joys and Perils of Mathematics. Kentucky: Ballantine.

Allen, J.P. (1992). Beyond Numeracy: Ruminations of a Numbers Man. Sacramento: Vintage Books.

Horton, J.C \& Guy, R.K. (1997). The Book of Numbers. Verlag: Springer.

Singh, Simon. (1998). Fermat's Enigma: The Epic Quest to Solve the World's Greatest Mathematical Problem. Bantam: Routledge.

Guillen, M. (1996). Five Equations That Changed the World: The Power and Poetry of Mathematics. Texas: Hyperion.

Brookhart, C. (1998). Go Figure: Using Math to Answer Everyday Imponderables. Washington: Contemporary Books.

Dunham, W.W. (1991). Journey Through Genius: The Great Theorems of Mathematics. Alabama: Penguin Books.

Blatner, David. (1997). The Joy of Pi. Long Island: Walker \& Co. 


\section{Jurnal}

JSSH SAINS SOSIAL dan HUMANIORA

Devlin, Keith J. (1998). Life by the Numbers. Englewood Cliffs, NJ: Wiley.

Stewart, Ian. (1998). The Magical Maze: Seeing the World Through Mathematical Eyes. MA: Newbury House.

Dunham, William, W. (1997). The Mathematical Universe: An Alphabetical Journey Through the Great Proofs, Problems and Personalities. Hillsdale, NJ: Erlbaum.

Allen, J.P. (1996). A Mathematician Reads the Newspaper. New York: Anchor Press.

Gullberg, J. \& Hilton, P.W. (1997). Mathematics: From the Birth of Numbers. Clearwater, FL: Norton Inc. 